\title{
Proactive, reactive, and romantic relational aggression in adulthood: Measurement, predictive validity, gender differences, and association with Intermittent Explosive Disorder
}

\author{
Dianna Murray-Close \\ University of Vermont \\ Jamie M. Ostrov \\ SUNY University at Buffalo \\ David A. Nelson \\ Brigham Young University - Provo, david_nelson@byu.edu \\ Nicki R. Crick

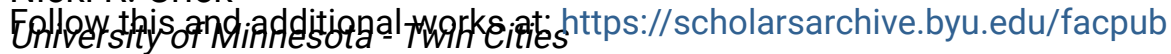 \\ Part of the Other Social and Behavioral Sciences Commons \\ Emil F. Coccaro \\ University of Chicago
}

Original Publication Citation

Murray-Close, D., Ostrov, J. M., Nelson, D. A., Crick, N. R., \& Coccaro, E. F. (2010). Proactive, reactive, and romantic relational aggression in adulthood: Measurement, predictive validity, gender differences, and association with intermittent explosive disorder. Journal of Psychiatric Research, 44, 393-404.

\section{BYU ScholarsArchive Citation}

Murray-Close, Dianna; Ostrov, Jamie M.; Nelson, David A.; Crick, Nicki R.; and Coccaro, Emil F., "Proactive, reactive, and romantic relational aggression in adulthood: Measurement, predictive validity, gender differences, and association with Intermittent Explosive Disorder" (2009). Faculty Publications. 4560. https://scholarsarchive.byu.edu/facpub/4560

This Peer-Reviewed Article is brought to you for free and open access by BYU ScholarsArchive. It has been accepted for inclusion in Faculty Publications by an authorized administrator of BYU ScholarsArchive. For more information, please contact ellen_amatangelo@byu.edu. 


\title{
Proactive, reactive, and romantic relational aggression in adulthood: Measurement, predictive validity, gender differences, and association with Intermittent Explosive Disorder
}

\author{
Dianna Murray-Close ${ }^{\mathrm{a}, *}$, Jamie M. Ostrov ${ }^{\mathrm{b}}$, David A. Nelson ${ }^{\mathrm{c}}$, Nicki R. Crick ${ }^{\mathrm{d}}$, Emil F. Coccaro ${ }^{\mathrm{e}}$ \\ a Department of Psychology, University of Vermont, United States \\ ${ }^{\mathrm{b}}$ Department of Psychology, University at Buffalo, The State University of New York, United States \\ ' School of Family Life, Brigham Young University, United States \\ ${ }^{\mathrm{d}}$ Institute of Child Development, University of Minnesota, Twin Cities Campus, United States \\ ${ }^{\mathrm{e}}$ Department of Psychiatry, University of Chicago, United States
}

\section{A R T I C L E I N F O}

\section{Article history:}

Received 7 June 2009

Received in revised form 4 September 2009

Accepted 8 September 2009

\section{Keywords:}

Relational aggression

Proactive and reactive aggression

Intermittent Explosive Disorder

\begin{abstract}
A B S T R A C T
The psychometric properties of a recently introduced adult self-report of relational aggression are presented. Specifically, the predictive utility of proactive and reactive peer-directed relational aggression, as well as romantic relational aggression, are explored in a large $(N=1387)$ study of adults. The measure had adequate reliability and validity and the subscales demonstrated unique predictive abilities for a number of dependent variables. In particular, reactive but not proactive relational aggression was uniquely associated with history of abuse, hostile attribution biases, and feelings of distress regarding relational provocation situations. Reactive relational aggression was also more strongly related to anger and hostility than proactive aggression. In addition, relational aggression in the context of romantic relationships was uniquely related to anger, hostility, impulsivity, history of abuse, hostile attribution biases, and emotional sensitivity to relational provocations, even when controlling for peer-directed relational aggression. Gender differences in overall levels of relational aggression were not observed; however, males were most likely to engage in peer-directed proactive and reactive relational aggression whereas females were most likely to engage in romantic relational aggression. In a second study $(N=150)$, relational aggression was higher in a sample of adults with Intermittent Explosive Disorder than in a sample of healthy controls or psychiatric controls. The findings highlight the importance of assessing subtypes of relational aggression in adult samples. Ways in which this measure may extend research in psychology and psychiatry are discussed.
\end{abstract}

() 2009 Elsevier Ltd. All rights reserved.

\section{Introduction}

An important contributor to maladaptive functioning in both childhood and adulthood is involvement in aggressive conduct (Crick et al., 1999). Recently, investigators have emphasized the importance of examining the correlates of relational forms of aggression (e.g., social exclusion) in addition to the physical forms of aggressive conduct (e.g., hitting, assault) that have traditionally captured the majority of empirical attention (Crick and Grotpeter, 1995). The purpose of the present study was to validate a measure of relational aggression in adulthood and examine the factors associated with each subtype (i.e., proactive, reactive, and romantic) of

\footnotetext{
* Corresponding author. Address: 210A John Dewey Hall, Department of Psychology, University of Vermont, Burlington, VT 05405, United States. Tel.: +1 802656 4142; fax: +1 8026568783.

E-mail address: dmurrayc@uvm.edu (D. Murray-Close).
}

relational aggression. Moreover, given the lack of research assessing gender differences in relational aggression in adulthood, we explored whether men and women differed in their use of each subtype of relational aggression. Finally, we examined whether relational aggression was elevated in a group of adults with a history of impulsive aggression (i.e., Intermittent Explosive Disorder).

Aggression, defined as behaviors intended to hurt, harm, or injure another person (see Dodge et al., 2006) can vary in form. Physical aggression, which harms others via physical force or the threat of physical force, consists of such behaviors as hitting, pushing, kicking and punching (Dodge et al., 2006; Crick and Grotpeter, 1995). Relational aggression, in which the relationship serves as the vehicle of harm, includes spreading malicious rumors, lies, gossip or secrets, as well as intentionally ignoring (i.e., silent treatment) or excluding a person from an activity or group interaction (Crick and Grotpeter, 1995). Relational aggression may be manifested in both direct and covert ways (Crick et al., 1999), which 
distinguishes it from similar aggression constructs such as indirect aggression (see Björkqvist, 1994).

Although a substantial body of research has provided evidence that involvement in relationally aggressive behavior in childhood and adolescence is associated with maladaptive outcomes (see Crick et al., 1999), little work has examined the correlates of relational aggression in adulthood. The limited studies indicate that relationally aggressive behavior among emerging adults (18-25year-olds) is associated with serious adjustment difficulties (Burton et al., 2007; Goldstein et al., 2008; Lento-Zwolinski, 2007; Miller and Lynam, 2003; Storch et al., 2004; Werner and Crick, 1999). Additional research with older samples is clearly warranted.

However, one limitation of studies assessing relational aggression in adulthood is a lack of reliable and valid measures. Indeed, the majority of published relational aggression measures have been developed for use during early and middle childhood and most rely upon peer nominations, observations, and teacher-report methods (for a review, see Crick et al., 2007). This is a significant limitation if a researcher or clinician wants to assess relational aggression among individuals in non-group contexts (e.g., clinical practice) or when other informants are not available or may not be knowledgeable about the participants' behavior (see Little et al., 2003).

An important consideration in the measurement of adult relational aggression is the function of such aggressive behavior. Psychologists and psychiatrists have distinguished aggressive behaviors that are planned and displayed to serve a goal-directed end (i.e., proactive aggression or premeditated aggression) from those that are more impulsive and displayed in response to a perceived threat and out of hostility or anger (i.e., reactive aggression or impulsive aggression (Dodge, 1991; Standford et al., 2003; Vitaro et al., 1998). Moreover, a number of studies have documented the divergent nature of proactive and reactive aggression (Dodge and Coie, 1987; Fite et al., 2006; Poulin and Boivin, 2000; Pulkkinen, 1996; Raine et al., 2006), including evidence supporting the discriminant validity of these functions of aggression (Card and Little, 2006; Crick and Dodge, 1996; Day et al., 1992; Dodge et al., 1997; Hubbard et al., 2001, 2004, 2002; Price and Dodge, 1989; Salmivalli and Nieminen, 2002; Standford et al., 2003; Vitaro et al., 1998; Waschbusch et al., 2002; Waschbusch et al., 1998). Thus, in the present study, the measure of relational aggression in adulthood included subscales assessing both proactive and reactive functions of relational aggression.

Despite these recent advances, most research examining the unique correlates of proactive and reactive functions of aggression have focused on physical forms of aggression in child or adolescent samples. In these studies, consistent with its emotional nature, reactive physical aggression is associated with impulsivity, hostility, anger, and skin conductance reactivity during a provoking task (Hubbard et al., 2002; Raine et al., 2006). Reactive aggression is also associated with hostile attribution bias (HAB), or the tendency to assume that others' intentions are malicious during ambiguous conflict situations (Crick and Dodge, 1996; Dodge and Coie, 1987; Schwartz et al., 1998; for a meta-analysis, see Orobio de Castro et al., 2005; for a review, see Crick and Dodge, 1994). In regard to relational aggression, researchers have similarly found it to be associated with $\mathrm{HAB}$ and feelings of distress following ambiguous provocation. However, whereas physically aggressive individuals exhibit $\mathrm{HAB}$ regarding instrumental provocations (e.g., damage to property or physical harm), relationally aggressive children display HAB regarding relational provocations (e.g., relational slights or social exclusion; Crick, 1995; Crick et al., 2002; cf., Nelson et al., 2008a; see Bailey and Ostrov (2008) for a study with young adults). Finally, researchers have found that history of childhood abuse is associated with reactive, but not proactive, aggression (Dodge et al., 1997).
Beyond functions of aggression, another important consideration in the measurement of adult relational aggression is the context in which the aggression occurs. Most research with children and adolescents focuses on relational aggression enacted against peers or friends (e.g., Crick and Grotpeter, 1995; Grotpeter and Crick, 1996). However, as romantic relationships emerge in adolescence and become increasingly salient into adulthood (Furman and Buhrmester, 1985), it is important to explore the use of relational aggression in the context of such relationships. Indeed, initial work indicates that relational aggression enacted against romantic partners is associated with romantic relationships of relatively low quality (Linder et al., 2002) and with indices of maladjustment (e.g., depression, drug and alcohol use, Bagner et al., 2007). As such, a valid measure of adult relational aggression should attend to these behaviors occurring between romantic partners.

This study also examines whether adult relational aggression is tied to gender. In childhood, gender differences in relational aggression are often but not always documented, with girls exhibiting greater levels of relational aggression than boys (see Crick et al., 2007 for review). However, assessments of gender differences in relational aggression during adulthood are more limited. As males and females enter adolescence and adulthood, cross-sex interactions become increasingly common (Maccoby, 1990). As a result, the relationally aggressive behaviors more characteristic of elementary school girls may become more common among males as mixed-sex interactions increase. In fact, preliminary research with young adults suggests that there are no gender differences in relational aggression (e.g., Bailey and Ostrov, 2008; Basow et al., 2007; Burton et al., 2007; Loudin et al., 2003) or that males are more relationally aggressive than females (Storch et al., 2004). In addition, studies have found no differences in the use of relational aggression against a romantic partner (Linder et al., 2002).

Finally, limited research is available addressing the association between relational aggression and clinical diagnoses in adulthood. However, preliminary research with children suggests that heightened levels of relational aggression are associated with clinical problems such as ADHD (e.g., Zalecki and Hinshaw, 2004), ODD (Keenan et al., 2008; Ohan and Johnston, 2005) and Borderline features (Crick et al., 2005). In a similar vein, relational aggression may be associated with clinically-relevant disorders among adults. For example, adults with intermittent explosive disorder (IED), a disorder characterized by impulsive aggressive outburst, may also exhibit elevated levels of relational aggression. In fact, a recent study demonstrated that adults with IED were more likely than their peers to exhibit a hostile attribution bias regarding ambiguous provocations (Coccaro et al., 2009), which is a risk factor for involvement in aggression (Crick and Dodge, 1994). Thus, our final goal was to examine whether adults with IED engaged in heightened levels of relational aggression. In addition, given the overlap between physical and relational aggression in previous studies, we examined whether the association between IED and relational aggression remained when controlling for participants' physically aggressive conduct. This analysis allowed us to investigate the utility of including measures of relational aggression, in addition to traditional measures of physical aggression, in clinical settings.

\subsection{Goals and hypotheses}

Few psychometrically sound methods are currently available for investigating relational aggression in adulthood. The first goal of the present study was to evaluate the psychometric properties of a self-report measure of relationally aggressive behavior (developed by Morales and Crick, 1998) in a large $(N=1387)$ community sample of adults (Study 1 ). To date, this instrument has been used only with college samples (e.g., Bailey and Ostrov, 2008; Goldstein et al., 2008; Lento-Zwolinski, 2007; Miller and Lynam, 2003; 
Ostrov and Houston, 2008). Several hypotheses were tested in relation to this goal. First, romantic relational aggression, peer-directed proactive relational aggression, and peer-directed reactive relational aggression were expected to exhibit good internal consistency and stability over time. Second, it was expected that a confirmatory factor analysis (CFA) would confirm that a three-factor model would yield the best fit for the data. In addition, the inter-correlations between these subscales were predicted to be moderate in nature, indicating the shared but yet unique components of each construct. Third, in keeping with past findings (e.g., Dodge et al., 1997; Hubbard et al., 2002) we predicted that reactive relational aggression would be uniquely correlated with indices of anger, impulsivity, hostility, abuse, $\mathrm{HAB}$, and feelings of distress following relational provocation. Fourth, we expected romantic relational aggression to be uniquely associated with all of these indices, even when controlling for peer-directed proactive and reactive aggression. The second goal was to examine gender differences in relational aggression in adulthood; given previous research findings (e.g., Bailey and Ostrov, 2008), no gender differences in relational aggression were expected. The third goal was to examine whether relational aggression was elevated in adults with a history of impulsive aggression (i.e., IED) when compared to healthy controls and psychiatric controls $(N=150$; Study 2 ). We expected that adults with IED would exhibit heightened levels of relational aggression when compared to their peers, and that this effect would persist even when controlling for physically aggressive conduct.

\section{Study 1: psychometric properties of self reports of relational aggression}

\subsection{Method}

\subsubsection{Participants}

The participants in this study included unrelated male and females from a population-based twin sample from the PENN Twins Cohort (Coccaro and Jacobson, 2006) who completed a variety of questionnaires in a mailed survey. Data from only one member of any twin pair (i.e., where both members responded to the survey), randomly selected, were used in this study. Participants in the study ( 800 females and 587 males) ranged in age from 25 to 45 per inclusion criteria of the twin cohort $(M$ age $=33.80$, $S D=5.89$ ). Mean income was between $\$ 50,000$ and $\$ 75,000$. The racial profile of the participant sample showed an overrepresentation of Caucasian participants as compared with African-American and other races, with Caucasian participants representing approximately $93 \%$ of the total sample.

\subsubsection{Procedure}

The mailed survey was conducted according to the method of Dillman (Dillman, 2000) and had a response rate of approximately $71 \%$. Participants were given $\$ 10$ with the survey form which they kept whether or not they completed the survey. The surveys were returned to a third-party research organization (Research Data Inc., Richmond, VA) who scanned the survey results and checked all data prior to sending it to the investigators.

\subsubsection{Measures}

Self-Report of Aggression and Social Behavior Measure (SRASBM). The SRASBM is an instrument developed by Morales and Crick (1998). Two subscales concerning romantic relational aggression and victimization were recently used in Linder et al. (2002) and had acceptable Cronbach's $\alpha$ 's. The full measure consists of 16 relational aggression items. Specifically, 5 assess peer-directed proactive relational aggression (e.g., "I have threatened to share private information about my friends with other people in order to get them to comply with my wishes"), 6 assess peer-directed reactive relational aggression (e.g., "When I am not invited to do something with a group of people, I will exclude those people from future activities"), and 5 assess romantic relational aggression (e.g., "If my romantic partner makes me mad, I will flirt with another person in front of him/her"). The romantic relational aggression subscale includes items that assess both proactive and reactive functions. However, there were not enough items to consider these functions separately (i.e., only 1 proactive item). Subscale scores were calculated by computing the mean of all items in the subscale, with higher scores indicating higher levels of relational aggression. In the present study, the response scale for the SRASBM was adapted from its original 7-point scale to range from 0 ("never") to 4 ("very often"). The SRASBM has been used in a few recent studies and acceptable internal consistency has been demonstrated for a total relational aggression scale (Goldstein et al., 2008; Miller and Lynam, 2003; Schad et al., 2008) as well as for proactive and reactive relational aggression subscales (Bailey and Ostrov, 2008; Lento-Zwolinski, 2007). In addition, one-month test-retest reliability has been excellent $(r>.75)$ for proactive and reactive functions of relational peer aggression (Ostrov and Houston, 2008).

Buss-Perry Aggression Questionnaire (BPAQ; Buss and Perry, 1992). The BPAQ is a 29-item self-report questionnaire including subscales assessing anger ( 7 items, e.g., "I have trouble controlling my temper") and hostility ( 8 items, e.g., "I wonder why sometimes I feel so bitter about things"). This measure also includes subscales of physical aggression and verbal aggression that were not used in the present study. The items are scored on a five-point scale ranging from 1 ("extremely uncharacteristic of me") to 5 ("extremely characteristic of me)." Items for each subscale were summed to yield anger and hostility subscales, respectively.

Barratt Impulsiveness Scale (BIS-11; Patton et al., 1995). The BIS11 is a 34 item self-report questionnaire developed to assess impulsive behavior, taking into account the multi-factorial nature of the construct (e.g., "I don't pay attention," "I say things without thinking," "I act on impulse"). Each item is scored on a four-point scale: 1 ("rarely/never"), 2 ("occasionally"), 3 ("often"), and 4 ("almost always/always"). Items are then summed to yield a total impulsivity score. Past internal consistency reliability coefficients for the BIS-11 ranged from .79 to .83 (Patton et al., 1995).

Childhood Trauma Questionnaire (CTQ; Bernstein et al., 1994). The CTQ is a self-administered measure that assesses five types of childhood maltreatment: emotional abuse (e.g., "Called names by family"), physical abuse (e.g., "Hit hard enough to leave bruises"), sexual abuse (e.g., "Was touched sexually"), emotional neglect (e.g., "Did not feel loved") and physical neglect ("Wore dirty clothes"). Responses are coded on a five-point scale that ranges from 1 ("never true") to 5 ("very often true"). Higher scores indicate more severe abuse or neglect. The CTQ has been validated in more than 2000 participants from clinical and community samples. Reliability (Cronbach's $\alpha$ 's) of the scales ranges from .66 to .92 (e.g., Bernstein and Fink, 1998; Bernstein et al., 1994). Scores are stable over time and show criterion validity as well as convergent and discriminant validity with other abuse instruments (Bernstein et al., 1994).

State-Trait Anger Expression Inventory (STAXI; Spielberger, 1996). The STAXI is a 44-item self-report instrument that assesses state and trait anger. The STAXI measures the intensity of feelings of anger (state anger), the disposition to experience anger (trait anger), behaviorally expressed anger (anger-out), suppressed anger (anger-in), and self-control of anger behavior (anger control). Trait anger is composed of two subscales, angry temperament, which measures a general propensity to experience and express anger without provocation, and angry reaction, which measures the dis- 
position to express anger when criticized or treated unfairly by others. In addition, anger expression and its major components (i.e., anger out, anger in, anger control) are measured. The items are scored on a 4-point scale that ranges from 1 ("not at all") to 4 ("very much so"). Available internal consistency reliability coefficients for the STAXI (Cronbach's $\alpha$ 's) range from .64 to .92 (Spielberger, 1996).

Assessment of attribution and emotional response to socially ambiguous stimuli (social information processing-attribution and emotion response questionnaire: SIP-AERQ). The SIP-AERQ consisted of eight vignettes written specifically for adults modeled after similar vignettes used by Crick et al. (2002) (see Coccaro et al., 2009). Each vignette presented a socially ambiguous situation in which an adverse action is directed at the person who the participant is asked to identify with. Although the measure includes vignettes of instrumental ( 4 items; e.g., being hit by someone) and relational provocation (4 items; e.g., a friend shares one of your secrets), only the relational provocation items were included in the present study. Each vignette was then followed by four Likert-scaled questions that assessed direct hostile intent (e.g., "My friend wanted me to feel stupid for asking to keep my secret"), indirect hostile intent (e.g., "My friend wanted to expose my secret"), instrumental non-hostile intent (e.g., "My friend wanted to impress other people with their secret knowledge about me"), and neutral or benign intent (e.g., "My friend forgot that this was an important secret for me"). Scores for the hostile intent (direct or indirect) were summed across vignettes to yield an overall hostile intent attribution score (scores for instrumental and benign intent were not included in this study). The four attribution items were followed by two items designed to reflect negative emotional response (i.e., "How likely is it that you would be angry if this happened to you?" and "How likely is it that you would be upset with yourself if this happened to you?"). The emotional response items were followed by the same Likert ratings as the four attribution items, which ranged from 0 ("Not at all likely") to 3 ("Very likely"). Scores for the two emotional response items were summed across vignettes to yield an overall emotional reactivity score. Previous research has documented the favorable psychometric properties of this measure, including factor structure, reliability, and convergent and discriminant validity (Coccaro et al., 2009). These response items were adapted from similar items currently being used in assessments in the laboratory of Kenneth Dodge, Ph.D.

\subsection{Results}

\subsubsection{Subscale reliability and short-term stability}

Results indicated adequate reliability for the aggression subscales. Alpha coefficients for the Total SRASBM score and for the three SRASBM subscale scores were .83 for Total Relational Aggression, .69 for Peer-directed Proactive Relational Aggression, .72 for Peer-directed Reactive Relational Aggression, and .66 for Romantic Relational Aggression. In addition, we examined the stability of the relational aggression scales in a sub-study of 153 of 200 twin subjects, selected at random, tested on two occasions, separated by about eight months (mean 8.0 +0.6 months, range $=6-9$ months). The longitudinal correlations were: .66 $(p<.001)$ for Total Relational Aggression, $.59(p<.001)$ for Peer-directed Proactive Relational Aggression, .65 $(p<.001)$ for Peer-directed Reactive Relational Aggression, and .68 $(p<.001)$ for Romantic Relational Aggression.

\subsubsection{Factor structure and distinction of constructs}

Confirmatory factor analyses were carried out using the Mplus program. In line with empirically derived arguments which suggest that Likert-type data should be treated as ordinal scales rather than as interval variables in statistical analysis, particularly when there is skewness in the indicators (see Yang et al., 2004, for a review), self reports of relational aggression were treated as categorical rather than continuous. A confirmatory factor analysis was run to test the measurement of the relational aggression constructs: (Peer-directed) Proactive Relational Aggression, (Peer-directed) Reactive Relational Aggression, and Romantic Relational Aggression. Preliminary results indicated that two items cross-loaded on two factors; thus, these items were dropped, yielding an overall measure of 14 items. Standardized factor loadings for each item are presented in Table 1 . The three-factor measurement model of the aggression constructs (i.e., proactive, reactive, and romantic) fit the data of the sample satisfactorily, as shown by the goodness of fit indices at the base of Table 1 . Inter-correlations among the three different latent constructs indicated that proactive and reactive peer-directed aggression were highly correlated $(\varphi=.85$, $p<.0001)$. Romantic relational aggression was also correlated with proactive $(\varphi=.75, p<.0001)$ and reactive $(\varphi=.68, p<.0001)$ peerdirected relational aggression.

The relatively high correlations obtained between the constructs led us to test for the distinction of constructs. Thus, the

Table 1

Standardized Factor Loadings of the Aggression Constructs and Goodness of Fit Indices.

\begin{tabular}{|c|c|c|}
\hline Item \# & Content & \\
\hline \multicolumn{3}{|c|}{ Peer-directed proactive relational aggression items } \\
\hline B & My friends know that I will think less of them if they do not do what I want them to do & .71 \\
\hline $\mathrm{D}$ & When I want something from a friend of mine, I act "cold" or indifferent towards them until I get what I want & .80 \\
\hline $\mathrm{J}$ & I have threatened to share private information about my friends with other people in order to get them to comply with my wishes & .77 \\
\hline $\mathrm{P}$ & I have intentionally ignored a person until they gave me my way about something & .80 \\
\hline \multicolumn{3}{|c|}{ Peer-directed reactive relational aggression items } \\
\hline C & When I am not invited to do something with a group of people, I will exclude those people from future activities & .68 \\
\hline $\mathrm{F}$ & $\begin{array}{l}\text { When I have been angry at, or jealous of someone, I have tried to damage that person's reputation by gossiping about him or her or by passing on } \\
\text { negative information about him/her to other people }\end{array}$ & .68 \\
\hline G & When someone does something that makes me angry, I try to embarrass that person or make them look stupid in front of his/her friends & .72 \\
\hline I & When I am mad at a person, I try to make sure she/he is excluded from group activities (going to the movies or to a bar) & .74 \\
\hline $\mathrm{L}$ & I have spread rumors about a person just to be mean & .70 \\
\hline \multicolumn{3}{|c|}{ Relational aggression in romantic relationships items } \\
\hline A & I have threatened to break up with a romantic partner in order to get him/her to do what I wanted & .69 \\
\hline E & I have tried to make my romantic partner jealous when mad at him/her & .81 \\
\hline $\mathrm{K}$ & I have cheated on my romantic partner because I was angry at him/her & .60 \\
\hline M & I have given my romantic partner the silent treatment when my feelings were hurt in some way by him or her & .58 \\
\hline 0 & If my romantic partner makes me mad, I will flirt with another person in front of him/her & .76 \\
\hline
\end{tabular}

Note: Goodness of fit: $\chi^{2}=322.68, d f=53, p<.0001, \mathrm{TLI}=.97, \mathrm{CFI}=.95$, RMSEA $=.06$. 
second step in analysis was to test competing models regarding the relative independence of the three aggression constructs with weighted least-squares estimation. Our baseline model was a three-construct model, in which separate aggression constructs (items representing proactive relational, reactive relational, and romantic relational aggression) were hypothesized to provide the best fit for the data. Tests of competing models, in which one or more of the constructs were merged, were completed and the results compared with the baseline model.

Table 2 shows the results of analyses we conducted to compare the baseline model with competing one- and two-factor models. A one-factor model reflects the collapse of all aggression subtypes into one solitary aggression (Proactive + Reactive + Romantic) construct. In contrast, two-factor models included several iterations in which two of three aggression constructs were collapsed. For example, one two-factor model was based on the collapse of the Proactive Relational and Reactive Relational aggression factors, thereby yielding a model which included Romantic Relational aggression and Proactive/Reactive Relational aggression as constructs.

Each of the competing models were compared with the baseline model. As indicated in Table 2, the chi-square of these competing models increased significantly, which implies greater discrepancy between the models and the data. Accordingly, competing models did not fit the data as well as the baseline three-construct model. Table 2 shows the chi-square difference $\left(\chi_{\text {diff }}^{2}\right)$ and corresponding

Table 2

Comparison of the baseline model with competing two-factor and one-factor alternatives.

\begin{tabular}{lllll}
\hline & $P+R$ & $R+$ ROM & $P+$ ROM & $P+R+$ ROM \\
\hline$\chi_{\text {diff }}^{2}$ & 72.35 & 175.40 & 110.76 & 202.32 \\
$d f_{\text {diff }}$ & 2 & 2 & 2 & 3 \\
$p$ & $<.0001$ & $<.0001$ & $<.0001$ & $<.0001$ \\
\hline
\end{tabular}

Note: $P+R=$ proactive and reactive relational aggression treated as one construct in the model.

$R+\mathrm{ROM}=$ reactive and romantic relational aggression treated as one construct in the model.

$P+\mathrm{ROM}=$ proactive and romantic relational aggression treated as one construct in the model.

$P+R+R O M=$ proactive, reactive, and romantic relational aggression treated as one construct in the model. differences in the degrees of freedom $\left(d f_{\text {diff }}\right)$ for each analysis. The chi-square difference indicates the increase in the chi-square relative to the baseline model. Thus, the three aggression constructs are well distinguished, even though they are highly correlated.

\subsubsection{Unique role of proactive and reactive relational aggression in predicting outcomes}

In addition to assessing the factor structure of the SRASBM, we examined the predictive validity of the proactive and reactive relational aggression subscales. Because reactive aggression is enacted in response to provocation or frustration (Crick and Dodge, 1996), we expected that reactive relational aggression would be uniquely associated with anger, hostility, impulsivity, hostile attribution bias, and emotional distress. As noted earlier, we also expected it to be associated with a history of abuse. To assess the unique role of proactive and reactive relational aggression in predicting these concurrent outcomes, a series of hierarchical regressions were conducted. In particular, each set of analyses were performed twice, with the order of entry of the independent variables reversed in order to allow for the assessment of the unique contributions of peer-directed proactive and reactive aggression. The dependent variables consisted of the following scales: Buss-Perry anger scale, Buss-Perry hostility scale, BIS, CTQ STAXI, hostile attribution bias in response to relational provocations, and emotional distress in response to relational provocations. In the first set of regressions, we examined the unique association between proactive relational aggression and these concurrent outcomes. In each regression, reactive relational aggression was entered at Step 1, and proactive relational aggression was entered at Step 2 . The results, presented in Table 3, indicated that proactive relational aggression was uniquely associated with anger (Buss-Perry and STAXI), hostility, and impulsivity above and beyond reactive relational aggression.

In the second set of analyses, proactive relational aggression was entered at Step 1, and reactive relational aggression was entered at Step 2. This allowed us to examine the unique association between reactive relational aggression and each outcome variable. The results, presented in Table 4, indicated that reactive relational aggression, above and beyond proactive relational aggression, was significantly associated with anger (Buss-Perry and STAXI), hostility, impulsivity, abuse, hostile intent attributions in response to

Table 3

Unique associations between proactive relational aggression and outcome variables.

\begin{tabular}{|c|c|c|c|c|c|c|c|}
\hline Model & Dependent variable & Step & Predictor & $\mathrm{B}$ & $t$-Value & $R^{2}, \Delta R^{2}$ & $F, \Delta F$ \\
\hline 1 & BPAQ anger & $\begin{array}{l}1 \\
2\end{array}$ & $\begin{array}{l}\text { Reactive Rel Agg } \\
\text { Proactive Rel Agg }\end{array}$ & $\begin{array}{l}.28^{* * * *} \\
.11^{* * *}\end{array}$ & $\begin{array}{r}10.81 \\
3.54\end{array}$ & $\begin{array}{l}.078 \\
.008\end{array}$ & $\begin{array}{l}116.86^{* * *} \\
12.53^{* * *}\end{array}$ \\
\hline 2 & BPAQ hostility & $\begin{array}{l}1 \\
2\end{array}$ & $\begin{array}{l}\text { Reactive Rel Agg } \\
\text { Proactive Rel Agg }\end{array}$ & $\begin{array}{l}.39^{* * * *} \\
.10^{* *}\end{array}$ & $\begin{array}{r}15.65 \\
3.17\end{array}$ & $\begin{array}{l}.151 \\
.006\end{array}$ & $\begin{array}{l}244.81^{* * *} \\
10.05^{* *}\end{array}$ \\
\hline 3 & BIS & $\begin{array}{l}1 \\
2\end{array}$ & $\begin{array}{l}\text { Reactive Rel Agg } \\
\text { Proactive Rel Agg }\end{array}$ & $\begin{array}{l}.17^{* * *} \\
.08^{*}\end{array}$ & $\begin{array}{l}6.27 \\
2.15\end{array}$ & $\begin{array}{l}.028 \\
.004\end{array}$ & $\begin{array}{l}39.36^{* * *} \\
5.85^{*}\end{array}$ \\
\hline 4 & CTQ & $\begin{array}{l}1 \\
2\end{array}$ & $\begin{array}{l}\text { Reactive Rel Agg } \\
\text { Proactive Rel Agg }\end{array}$ & $\begin{array}{l}.16^{* * *} \\
.04\end{array}$ & $\begin{array}{l}5.77 \\
1.25\end{array}$ & $\begin{array}{l}.024 \\
.001\end{array}$ & $\begin{array}{l}33.30^{* * *} \\
1.56\end{array}$ \\
\hline 5 & STAXI & $\begin{array}{l}1 \\
2\end{array}$ & $\begin{array}{l}\text { Reactive Rel Agg } \\
\text { Proactive Rel Agg }\end{array}$ & $\begin{array}{l}.37^{* * * *} \\
.16^{* * *}\end{array}$ & $\begin{array}{r}14.58 \\
5.19\end{array}$ & $\begin{array}{l}.134 \\
.017\end{array}$ & $\begin{array}{l}212.55^{* * *} \\
26.91^{* * *}\end{array}$ \\
\hline 6 & НАB & $\begin{array}{l}1 \\
2\end{array}$ & $\begin{array}{l}\text { Reactive Rel Agg } \\
\text { Proactive Rel Agg }\end{array}$ & $\begin{array}{l}.29^{* * *} \\
.05\end{array}$ & $\begin{array}{r}11.39 \\
1.50\end{array}$ & $\begin{array}{l}.087 \\
.002\end{array}$ & $\begin{array}{l}129.66^{* * *} \\
2.25\end{array}$ \\
\hline 7 & Feelings of distress & $\begin{array}{l}1 \\
2\end{array}$ & $\begin{array}{l}\text { Reactive Rel Agg } \\
\text { Proactive Rel Agg }\end{array}$ & $\begin{array}{l}.26^{* * *} \\
.01\end{array}$ & $\begin{array}{r}9.82 \\
.36\end{array}$ & $\begin{array}{l}.066 \\
.000\end{array}$ & $\begin{array}{l}96.42^{* * *} \\
.13\end{array}$ \\
\hline
\end{tabular}

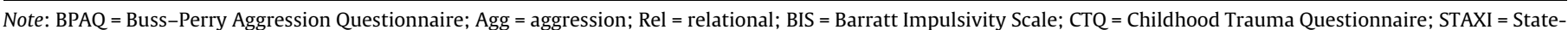
Trait Anger Expression Inventory; $\mathrm{HAB}=$ hostile attribution biases.

${ }^{*} p<.05$.

${ }^{* * *} p<.01$.

$p<.001$. 
Table 4

Unique associations between reactive relational aggression and outcome variables.

\begin{tabular}{|c|c|c|c|c|c|c|c|}
\hline Model & Dependent variable & Step & Predictor & B & $t$-Value & $R^{2}, \Delta R^{2}$ & $F, \Delta F$ \\
\hline 1 & BPAQ anger & $\begin{array}{l}1 \\
2\end{array}$ & $\begin{array}{l}\text { Proactive Rel Agg } \\
\text { Reactive Rel Agg }\end{array}$ & $\begin{array}{l}.24^{* * * *} \\
.22^{* * * *}\end{array}$ & $\begin{array}{l}9.02 \\
6.81\end{array}$ & $\begin{array}{l}.056 \\
.031\end{array}$ & $\begin{array}{l}81.35^{* * * *} \\
46.34^{* * *}\end{array}$ \\
\hline 2 & BPAQ hostility & $\begin{array}{l}1 \\
2\end{array}$ & $\begin{array}{l}\text { Proactive Rel Agg } \\
\text { Reactive Rel Agg }\end{array}$ & $\begin{array}{l}.29^{* * * *} \\
.33^{* * * *}\end{array}$ & $\begin{array}{l}11.19 \\
10.97\end{array}$ & $\begin{array}{l}.083 \\
.074\end{array}$ & $\begin{array}{l}125.16^{* * * *} \\
120.43^{* * *}\end{array}$ \\
\hline 3 & BIS & $\begin{array}{l}1 \\
2\end{array}$ & $\begin{array}{l}\text { Proactive Rel Agg } \\
\text { Reactive Rel Agg }\end{array}$ & $\begin{array}{l}.15^{* * * *} \\
.12^{* * * *}\end{array}$ & $\begin{array}{l}5.58 \\
3.73\end{array}$ & $\begin{array}{l}.022 \\
.010\end{array}$ & $\begin{array}{l}31.13^{* * * *} \\
13.92^{* * *}\end{array}$ \\
\hline 4 & CTQ & $\begin{array}{l}1 \\
2\end{array}$ & $\begin{array}{l}\text { Proactive Rel Agg } \\
\text { Reactive Rel Agg }\end{array}$ & $\begin{array}{l}.12^{* * * *} \\
.13^{* * * *}\end{array}$ & $\begin{array}{l}4.34 \\
3.98\end{array}$ & $\begin{array}{l}.014 \\
.011\end{array}$ & $\begin{array}{l}18.82^{* * * *} \\
15.84^{* * *}\end{array}$ \\
\hline 5 & STAXI & $\begin{array}{l}1 \\
2\end{array}$ & $\begin{array}{l}\text { Proactive Rel Agg } \\
\text { Reactive Rel Agg }\end{array}$ & $\begin{array}{l}.32^{* * * *} \\
.27^{* * * *}\end{array}$ & $\begin{array}{r}12.39 \\
9.00\end{array}$ & $\begin{array}{l}.100 \\
.050\end{array}$ & $\begin{array}{l}153.53^{* * * *} \\
81.00^{* * *}\end{array}$ \\
\hline 6 & HAB & $\begin{array}{l}1 \\
2\end{array}$ & $\begin{array}{l}\text { Proactive Rel Agg } \\
\text { Reactive Rel Agg }\end{array}$ & $\begin{array}{l}.20^{* * *} \\
.27^{* * *}\end{array}$ & $\begin{array}{l}7.64 \\
8.41\end{array}$ & $\begin{array}{l}.041 \\
.047\end{array}$ & $\begin{array}{l}58.29^{* * *} \\
70.76^{* * *}\end{array}$ \\
\hline 7 & Feelings of distress & $\begin{array}{l}1 \\
2\end{array}$ & $\begin{array}{l}\text { Proactive Rel Agg } \\
\text { Reactive Rel Agg }\end{array}$ & $\begin{array}{l}.16^{* * *} \\
.25^{* * *}\end{array}$ & $\begin{array}{l}5.86 \\
7.79\end{array}$ & $\begin{array}{l}.025 \\
.042\end{array}$ & $\begin{array}{l}34.33^{* * *} \\
60.66^{* * *}\end{array}$ \\
\hline
\end{tabular}

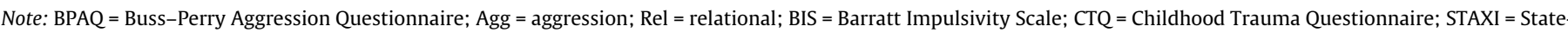
Trait Anger Expression Inventory; $\mathrm{HAB}=$ hostile attribution biases.

$p<.001$.

relational provocations, and emotional sensitivity in response to relational provocations.

Accordingly, only reactive relational aggression was associated with history of abuse, hostile attribution biases and emotional sensitivity. However, both proactive and reactive relational aggression were associated with anger, hostility and impulsivity. Follow-up analyses were run to examine the relative strength of the correlations between proactive and reactive relational these factors. Comparisons of correlations from the same sample (see Cohen and Cohen, 1983) indicated that reactive relational aggression was more strongly correlated with anger [Buss-Perry: $t(1375)=-2.11$, $p<.05$; STAXI: $t(1376)=-2.19, p<.05$ ] and hostility, $(t(1376)$ $=-4.39, p<.001$ ), than was proactive relational aggression. Thus, although both proactive and reactive relational aggression were associated with these outcomes, the association was stronger for reactive relational aggression.

\subsubsection{Unique role of romantic relational aggression in predicting outcomes}

In the next set of analyses, we examined the unique association between romantic relational aggression and the dependent variables. We expected that these factors would be uniquely associated with romantic relational aggression, even when controlling for proactive and reactive peer-directed relational aggression. To address this hypothesis, a series of hierarchical regression analyses were conducted. In each regression, proactive and reactive peer-directed relational aggression were entered at Step 1, and romantic relational aggression was then entered at Step 2. This allowed us

Table 5

Unique associations between romantic relational aggression and outcome variables.

\begin{tabular}{|c|c|c|c|c|c|c|c|}
\hline Model & Dependent variable & Step & Predictor & B & $t$-Value & $R^{2}, \Delta R^{2}$ & $F, \Delta F$ \\
\hline \multirow[t]{2}{*}{1} & \multirow[t]{2}{*}{ BPAQ anger } & 1 & $\begin{array}{l}\text { Proactive Rel Agg } \\
\text { Reactive Rel Agg }\end{array}$ & $\begin{array}{l}.12^{* * *} \\
.21^{* * *}\end{array}$ & $\begin{array}{l}3.63 \\
6.68\end{array}$ & .087 & $64.90^{* * *}$ \\
\hline & & 2 & Romantic Rel Agg & $.13^{* * *}$ & 4.11 & .011 & $16.89^{* * *}$ \\
\hline \multirow[t]{2}{*}{2} & \multirow[t]{2}{*}{ BPAQ hostility } & 1 & $\begin{array}{l}\text { Proactive Rel Agg } \\
\text { Reactive Rel Agg }\end{array}$ & $\begin{array}{l}.10^{* *} \\
.33^{* * *}\end{array}$ & $\begin{array}{r}3.16 \\
10.91\end{array}$ & .157 & \multirow[t]{2}{*}{$127.49^{* * * *}$} \\
\hline & & 2 & Romantic Rel Agg & $.14^{* * *}$ & 4.72 & .014 & \\
\hline \multirow[t]{2}{*}{3} & \multirow[t]{2}{*}{ BIS } & 1 & $\begin{array}{l}\text { Proactive Rel Agg } \\
\text { Reactive Rel Agg }\end{array}$ & $\begin{array}{l}.08^{*} \\
.12^{* * *}\end{array}$ & $\begin{array}{l}2.40 \\
3.73\end{array}$ & .032 & $22.65^{* * *}$ \\
\hline & & 2 & Romantic Rel Agg & $.17^{* * *}$ & 5.49 & .021 & $30.11^{* * *}$ \\
\hline \multirow[t]{2}{*}{4} & \multirow[t]{2}{*}{ CTQ } & 1 & $\begin{array}{l}\text { Proactive Rel Agg } \\
\text { Reactive Rel Agg }\end{array}$ & $\begin{array}{l}.04 \\
.13^{* * *}\end{array}$ & $\begin{array}{l}1.25 \\
3.90\end{array}$ & .025 & \multirow[t]{2}{*}{$16.99^{* * *}$} \\
\hline & & 2 & Romantic Rel Agg & $.10^{* *}$ & 2.99 & .006 & \\
\hline \multirow[t]{2}{*}{5} & \multirow[t]{2}{*}{ STAXI } & 1 & $\begin{array}{l}\text { Proactive Rel Agg } \\
\text { Reactive Rel Agg }\end{array}$ & $\begin{array}{l}.16^{* * *} \\
.27^{* * *}\end{array}$ & $\begin{array}{l}5.17 \\
8.91\end{array}$ & .15 & $120.48^{* * *}$ \\
\hline & & 2 & Romantic Rel Agg & $.16^{* * *}$ & 5.56 & .019 & $30.96^{* * *}$ \\
\hline \multirow[t]{2}{*}{6} & \multirow[t]{2}{*}{ HAB } & 1 & $\begin{array}{l}\text { Proactive Rel Agg } \\
\text { Reactive Rel Agg }\end{array}$ & $\begin{array}{l}.04 \\
.27^{* * *}\end{array}$ & $\begin{array}{l}1.39 \\
8.51\end{array}$ & .09 & $66.73^{* * *}$ \\
\hline & & 2 & Romantic Rel Agg & $.07^{*}$ & 2.19 & .003 & $4.81^{*}$ \\
\hline \multirow[t]{2}{*}{7} & \multirow[t]{2}{*}{ Feelings of Distress } & 1 & $\begin{array}{l}\text { Proactive Rel Agg } \\
\text { Reactive Rel Agg }\end{array}$ & $\begin{array}{l}.01 \\
.25^{* * *}\end{array}$ & $\begin{array}{r}.33 \\
7.77\end{array}$ & .066 & $47.95^{* * *}$ \\
\hline & & 2 & Romantic Rel Agg & $.15^{* * *}$ & 4.93 & .016 & $24.31^{* * * *}$ \\
\hline
\end{tabular}

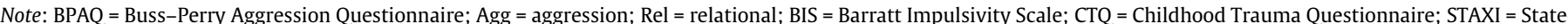
Trait Anger Expression Inventory; $\mathrm{HAB}=$ hostile attribution biases.

${ }^{*} p<.05$.

*** $p<.01$.

$p<.001$. 
to examine the unique relation between romantic relational aggression and each outcome, controlling for peer-directed aggression. The results, presented in Table 5 , indicated that romantic relational aggression was related to anger (Buss-Perry and STAXI), hostility, impulsivity, abuse, hostile attribution biases, and feelings of distress regarding relational provocation.

\subsubsection{Gender differences}

To explore possible gender differences for the subtypes of relationally aggressive behavior, a 3 (Aggression Subtype: Proactive, Reactive and Romantic Relational Aggression) $\times 2$ (gender) repeated measures analysis of variance (RM-ANOVA) was conducted with aggression scores serving as the repeated measure. A main effect for aggression subtype emerged, $F(2,1368)=442.21, p<.001$, $\eta^{2}=.39$. Follow-up contrasts indicated that romantic relational aggression $(M=.59 ; S D=.48)$ was more prevalent than reactive relational aggression $(M=.47 ; S D=.48)$, which was in turn more prevalent than proactive relational aggression $(M=.26, S D=.38)$. As expected, there were no gender differences in overall levels of the relational aggression subtypes. However, a significant interaction between aggression subtype and gender emerged, $F(2,1368)=48.41, p<.001, \eta^{2}=.07$. Follow-up analysis of variance (ANOVA) analyses examining gender differences in each subtype of aggression indicated that males were more proactively relationally aggressive $(M=.31, S D=.42)$ than females $(M=.22, S D=.35)$, $F(1,1383)=19.03, p<.001, \eta^{2}=.014$. In addition, males $(M=.53$, $S D=.51$ ) exhibited more reactive relational aggression than females $(M=.43, S D=.45), F(1,1380)=14.91, p<.001, \eta^{2}=.011$. However, females $(M=.65, S D=.50)$ engaged in more romantic relational aggression than males $(M=.52, S D=.44), F(1,1373)=$ 21.90, $p<.001, \eta^{2}=.016$.

\section{Study II: patient-control study}

\subsection{Method}

\subsubsection{Participants}

To assess the ability of the SRASBM to discriminate between participants with and without problems with aggression, 50 participants without any current or past history of Axis I or II Disorder, 50 participants with Axis I ( $n=25)$ and/or Axis II $(n=25)$ disorders, and 50 participants meeting DSM-IV Criteria for Personality Disorder and for Research Criteria for Intermittent Explosive Disorder were studied. These participants were independent from, and unrelated to, those participants included in Study 1 described above. These participants were recruited from the community from Public Service Announcements highlighting studies of personality style including aggressiveness. Participants with a life history of Bipolar disorder, Schizophrenia (or other psychotic disorder), or mental retardation were excluded from this study. Demographic characteristics of the Study 2 sample are shown in Table 6.

\subsubsection{Measures}

Structured Clinical Interview for the DSM-IV (SCID-I). The SCID is a semi-structured clinical interview used to assign diagnoses for mood disorders, psychotic disorders, substance abuse and dependence, anxiety disorders, somatoform disorders, eating disorders, and adjustment disorders (First et al., 1997). The purpose of administering the SCID was to diagnose DSM Axis I disorders. In this study, kappa values for the most frequent lifetime Axis I diagnoses were excellent (e.g., $\kappa=.85$ for Mood Disorder, $\kappa=.79$ for Anxiety Disorder; $\kappa=.93$ for Substance Dependence Disorder).

Structured Interview for DSM-IV Personality (SID-P). The SID-P was employed to diagnose DSM-IV personality disorders (Pfohl et al., 1997). In this study, the inter-rater reliability for the diagnosis of personality disorder was excellent at $\kappa=.83$.

Intermittent Explosive Disorder Interview (IED Interview). The IED interview (E.F. Coccaro, on request) is a semi-structured clinical interview that was used to diagnose IED by DSM-IV and by Research Criteria (IED-IR, Coccaro et al., 2004). The IED interview enables the interviewer to obtain quantitative (e.g., frequency) and qualitative (e.g., description of most severe events) information for verbal aggression, aggression against property, and aggression against others, as well as aggression-related distress and psychosocial impairment and potential exclusionary information (i.e., aggressive acts occurring solely within the context of another Axis I disorder, substance use, or a medical condition). The Inter-rater reliability of the IED-IR with the IED-M in this study was excellent $(\kappa=.82$ ).

Buss-Perry Aggression Questionnaire (BPAQ; Buss and Perry, 1992). Participants also complete the BPAQ (described in Study 1 ). The physical aggression subscale of the BPAQ includes 9 items (e.g., "Given enough provocation, I may hit another person") scored on a five-point scale ranging from 1 ("extremely uncharacteristic of me") to 5 ("extremely characteristic of me"). Items for each subscale were summed to yield a total physical aggression score.

\subsubsection{Procedure}

All participants completed the 14 items of the SRASBM validated in Study 1 (as described above) and the BPAQ. Participants then completed a structured clinical interview including the SCID, SID-P, and IED assessment. Fifty-nine participants underwent the SRASBM twice to assess test-retest reliability in this patient-control sample. Axis I and Axis II Personality Disorder (PD) diagnoses were made according to DSM-IV criteria (American Psychiatric Association, 1994). The diagnosis of Intermittent Explosive Disorder (IED) was made by using Integrated Research Criteria (IEDIR; Coccaro et al., 2004) which differ from DSM-IV criteria in that they require: (a) one-month (or more) period of aggressive

Table 6

Demographic, functional, and behavioral data: IED/PD vs. control participants for Study 2.

\begin{tabular}{|c|c|c|c|c|c|}
\hline Variable & IED/PD participants $(n=50)$ & Psych control participants $(n=50)$ & Healthy control participants $(n=50)$ & Statistic & $p$ \\
\hline \multicolumn{6}{|l|}{ Demographic } \\
\hline Age & $38.2 \pm 9.7$ & $36.6 \pm 12.7$ & $36.9 \pm 17.4$ & $F(2,147)=0.45$ & 636 \\
\hline Gender $(\mathrm{M} / \mathrm{F})$ & $26 / 24$ & $22 / 28$ & $29 / 21$ & $\chi^{2}=1.98, \mathrm{df}=2$ & .373 \\
\hline Race (White/non-White) & $30 / 20$ & $33 / 17$ & $34 / 16$ & $\chi^{2}=0.76, \mathrm{df}=2$ & .684 \\
\hline SES (I/II/III/IV/V) & $4 / 27 / 7 / 6 / 6$ & $5 / 26 / 10 / 3 / 6$ & $6 / 34 / 4 / 2 / 4$ & $\chi^{2}=7.15, \mathrm{df}=8$ & .521 \\
\hline $\begin{array}{l}\text { Functional } \\
\text { GAF }\end{array}$ & $58.5 \pm 7.3^{\mathrm{a}}$ & $69.0 \pm 10.8^{\mathrm{b}}$ & $86.1 \pm 4.7^{\mathrm{c}}$ & $F(2,147)=151.4$ & $<.001$ \\
\hline $\begin{array}{l}\text { Behavioral } \\
\text { BPAQ physical aggression }\end{array}$ & $26.8 \pm 10.2^{\mathrm{a}}$ & $18.5 \pm 8.5^{b}$ & $16.8 \pm 8.8^{\mathrm{b}}$ & $F(2,139)=15.94$ & $<.001$ \\
\hline
\end{tabular}

Note: Means in rows with different superscripts are significantly different from each other at $p<.05$. 
outbursts (including verbal outbursts only, or outbursts in which property is not destroyed) occurring twice a week on average, or at least three episodes of serious assaultive or destructive behavior in one year (even when there are not recurrent aggressive outbursts within the one-month time frame); (b) aggressive outbursts to be, primarily, impulsive in nature, (c) aggressive outbursts to be associated with significant subjective distress or psychosocial impairment. Final diagnoses were assigned by team best-estimate consensus procedures involving at least two research psychiatrists and two clinical psychologists as previously described (Klein et al., 1994). This methodology has previously been shown to enhance the accuracy of diagnosis over direct interview alone (Kosten and Rounsaville, 1992; Leckman et al., 1982).

\subsection{Results}

\subsubsection{Sample characteristics}

Axis I and Axis II disorder diagnoses for the 50 IED + and 50 psychiatric control participants are presented in Table 7. Among the IED + patients, all had a current and/or lifetime history of an Axis I and Axis II disorder. The distribution of Axis I or II diagnoses between the IED + and Psychiatric Control groups did not differ except the IED patients exhibited heightened incidence of IED (by definition; Fisher Exact $p<.001$ corrected for multiple compari- sons), Paranoid PD (Fisher Exact $p=.006$ corrected), Antisocial PD (Exact $p=.013$, corrected), and Borderline PD (Exact $p=.02$, corrected). Analysis of variance analyses indicated that participants diagnosed with Paranoid PD $[M=1.26, S D=.88$ versus $M=.64$, $\left.S D=.63, F(1,147)=6.17, p<.05, \eta^{2}=.04\right]$, Antisocial PD $[M=1.28$, $S D=.60$ versus $\left.M=.63, S D=.64, F(1,147)=8.83, p<.01, \eta^{2}=.06\right]$, and Borderline PD $[M=1.11, S D=.46$ versus $M=.63, S D=.65$, $\left.F(1,147)=6.14, p<.05, \eta^{2}=.04\right]$ exhibited heightened levels of total relational aggression when compared to their peers. By definition, the 50 Healthy Control participants had no current or past history of any Axis I or Axis II disorder.

\subsubsection{Basic psychometrics properties of the SRASBM in patient and control participants}

Alpha coefficients for Total Relational Aggression, Proactive Relational Aggression, Reactive Relational Aggression, and Romantic Relational Aggression in the patient-control sample $(N=150)$ were $.91, .80, .83$, and .78 , respectively. Alpha coefficients were similar in the patients and controls examined separately. Test-retest data on these variables was obtained on 59 of 75 participants selected at random for administration of the SRASBM a second time separated by about nine months (mean $9.1+0.9$ months, range $=6-11$ months). Pearson correlations for the SRASBM scales at retest were as follows: $r=.92$ for Total Relational Aggression, .91

Table 7

Number (and percentage) of IED/PD and psychiatric control participants with Axis I and Axis II diagnoses for Study 2.

\begin{tabular}{|c|c|c|c|c|}
\hline & \multicolumn{4}{|l|}{ Axis I disorders } \\
\hline & \multicolumn{2}{|c|}{ IED/PD participants $(n=50)$} & \multicolumn{2}{|c|}{ Psych control participants $(n=25)$} \\
\hline & Current diagnosis & Lifetime diagnosis & Current diagnosis & Lifetime diagnosis \\
\hline \multicolumn{5}{|l|}{ Mood disorders } \\
\hline Major depression & $9(18 \%)$ & $21(42 \%)$ & $4(16 \%)$ & $14(56 \%)$ \\
\hline Dysthymia & $6(12 \%)$ & $7(14 \%)$ & $3(12 \%)$ & $4(16 \%)$ \\
\hline Depressive disorder-NOS & $2(4 \%)$ & $4(8 \%)$ & $1(4 \%)$ & $4(16 \%)$ \\
\hline Any mood disorder & $13(26 \%)$ & $28(56 \%)$ & $7(28 \%)$ & $17(68 \%)$ \\
\hline \multicolumn{5}{|l|}{ Anxiety disorders } \\
\hline Post-traumatic stress disorder & $4(8 \%)$ & $6(12 \%)$ & $0(0 \%)$ & $2(8 \%)$ \\
\hline Specific Phobia & $4(8 \%)$ & $5(10 \%)$ & $0(0 \%)$ & $0(0 \%)$ \\
\hline Panic disorder & $3(6 \%)$ & $4(8 \%)$ & $1(4 \%)$ & $1(4 \%)$ \\
\hline Generalized anxiety disorder & $3(6 \%)$ & $3(6 \%)$ & $1(4 \%)$ & $1(4 \%)$ \\
\hline Obsessive-compulsive disorder & $2(4 \%)$ & $2(4 \%)$ & $0(0 \%)$ & $1(4 \%)$ \\
\hline Agoraphobia & $2(4 \%)$ & $2(4 \%)$ & $0(0 \%)$ & $0(0 \%)$ \\
\hline Social phobia & $1(2 \%)$ & $1(2 \%)$ & $2(8 \%)$ & $2(8 \%)$ \\
\hline Anxiety disorder-NOS & $1(2 \%)$ & $3(6 \%)$ & $3(12 \%)$ & $3(12 \%)$ \\
\hline Any anxiety disorder & $15(30 \%)$ & $19(38 \%)$ & $5(20 \%)$ & $8(32 \%)$ \\
\hline \multicolumn{5}{|l|}{ Impulse control disorders } \\
\hline IED by research criteria & $37(74 \%)$ & $50(100 \%)$ & $0(0 \%)$ & $0(0 \%)$ \\
\hline Pathological gambling & $1(2 \%)$ & $1(2 \%)$ & $0(0 \%)$ & $0(0 \%)$ \\
\hline Trichotillomania & $1(2 \%)$ & $1(2 \%)$ & $0(0 \%)$ & $0(0 \%)$ \\
\hline Eating disorders & $3(6 \%)$ & $7(14 \%)$ & $0(0 \%)$ & $4(16 \%)$ \\
\hline Adjustment disorders & $0(0 \%)$ & $3(6 \%)$ & $0(0 \%)$ & $2(8 \%)$ \\
\hline Somatoform disorders & $0(0 \%)$ & $1(2 \%)$ & $1(4 \%)$ & $1(4 \%)$ \\
\hline \multicolumn{5}{|l|}{ Substance use disorders } \\
\hline Alcohol dependence & $0(0 \%)$ & $11(22 \%)$ & $0(0 \%)$ & $13(52 \%)$ \\
\hline \multirow[t]{3}{*}{ Drug dependence } & $0(0 \%)$ & $7(14 \%)$ & $0(0 \%)$ & $4(16 \%)$ \\
\hline & \multicolumn{4}{|l|}{ Axis II disorders } \\
\hline & \multicolumn{2}{|c|}{ IED/PD participants $(n=50)$} & \multicolumn{2}{|c|}{ Psych control participants $(n=25)$} \\
\hline Paranoid & \multicolumn{2}{|l|}{$11(22 \%)$} & \multicolumn{2}{|l|}{$0(0 \%)$} \\
\hline Schizoid & \multicolumn{2}{|l|}{$0(0 \%)$} & \multicolumn{2}{|l|}{$1(4 \%)$} \\
\hline Borderline & \multicolumn{2}{|l|}{$12(24 \%)$} & \multicolumn{2}{|l|}{$1(4 \%)$} \\
\hline Antisocial & \multicolumn{2}{|l|}{$10(20 \%)$} & \multicolumn{2}{|l|}{$0(0 \%)$} \\
\hline Narcissistic & \multicolumn{2}{|l|}{$11(22 \%)$} & \multicolumn{2}{|l|}{$5(20 \%)$} \\
\hline Histrionic & \multicolumn{2}{|l|}{$2(4 \%)$} & \multicolumn{2}{|l|}{$0(0 \%)$} \\
\hline Obsessive-complusive & \multicolumn{2}{|l|}{$11(22 \%)$} & \multicolumn{2}{|l|}{$5(20 \%)$} \\
\hline Avoidant & \multicolumn{2}{|l|}{$5(10 \%)$} & \multicolumn{2}{|l|}{$3(12 \%)$} \\
\hline Dependent & $1(2 \%)$ & & $1(4 \%)$ & \\
\hline PD-NOS & $17(34 \%)$ & & $12(48 \%)$ & \\
\hline
\end{tabular}

Note: A number of participants had more than one diagnosis; thus, participants could be classified in more than one diagnostic category. 
for Proactive Relational Aggression, .84 for Reactive Relational Aggression, and .88 for Romantic Relational Aggression (each $p<.001)$.

\subsubsection{Patient-control differences}

IED participants demonstrated clear differences from the two control groups with all relational aggression variables. A three (Group: IED, Psychiatric Controls, Healthy Controls) by two (Gender) ANOVA with Total Relational Aggression serving as the dependent variable revealed a significant effect for Group $\left[F(2,144)=20.70, p<.001\right.$, partial $\left.\eta^{2}=.22\right]$, but not for Gender $[F(1,144)=0.00, p=.98]$ or Group $\times$ Gender $[F(1,144)=0.39$, $p=.68$ ]. Post-hoc analyses (Tukey HSD) revealed that IED participants had significantly $(p<.001)$ higher Total Relational Aggression scores than either Psychiatric or Healthy controls whose Relational Aggression scores, in turn, were not different from each other. This result was not altered when GAF scores (which differed significantly among the groups; see Table 6) were added to the model. The same results were found when the SRASBM subscales were examined (Fig. 1). In addition, since Paranoid PD, Antisocial PD, and Borderline PD were associated with IED status and with relational aggression scores, analyses were re-run controlling for these diagnoses; all significant effects were replicated. Finally, the analyses were re-run controlling for BPAQ Physical Aggression scores. All significant effects were replicated with this additional control.

\section{Discussion}

The first goal of the present study was to examine the psychometric properties of a self-report measure of relational aggression in adulthood. We replicated previous work suggesting adequate internal consistency of the SRASBM (e.g., Bailey and Ostrov, 2008; Linder et al., 2002). The test-retest reliability of the measure was also confirmed in two short-term longitudinal studies. In addition, this is the first study to provide support for the internal structure of the SRASBM. That is, factor analysis suggested the presence of the three hypothesized factors (i.e., proactive, reactive, and romantic relational aggression). The inter-correlations between the factors indicated moderate to large levels of association between the variables, which is consistent with past studies investigating proactive and reactive physical aggression (e.g., Dodge and Coie, 1987; Fite et al., 2006).

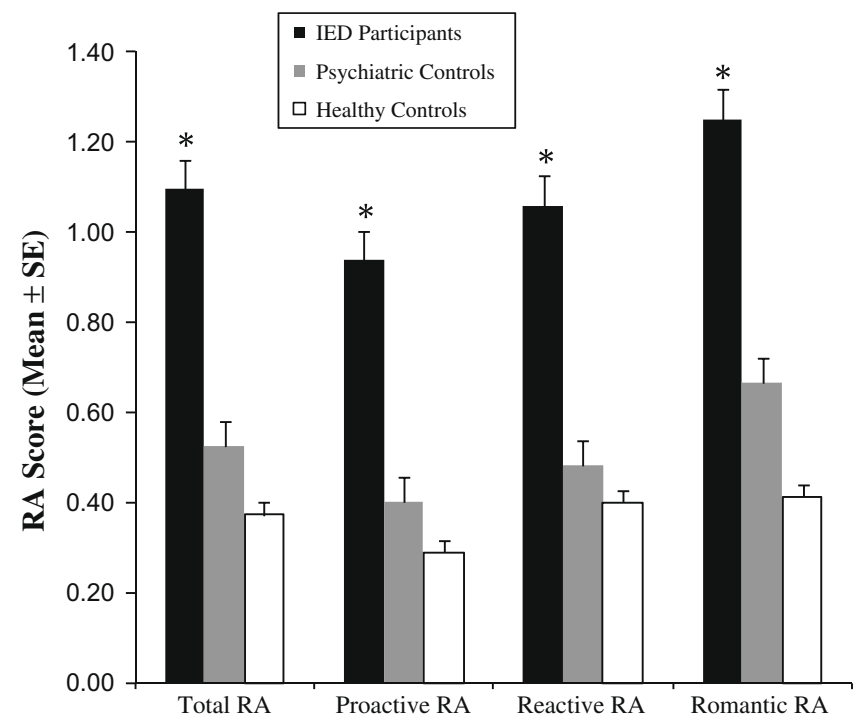

Fig. 1. Relational aggression in adults with IED, healthy controls, and psychiatric controls for Study 2. ${ }^{*} p<.001$.
As expected, only reactive relational aggression was uniquely associated with history of abuse, hostile attribution biases, and feelings of distress for relational provocation situations. In addition, although both proactive and reactive relational aggression were uniquely associated with hostility and anger, reactive relational aggression was more strongly associated with these outcomes than proactive relational aggression. This research replicates and extends past findings for physical aggression with younger samples. For example, the finding that only reactive relational aggression was associated with a history of abuse mirrors those found with reactive physical aggression in past studies with younger samples (Dodge et al., 1997). Overall, then, these results are consistent with previous research demonstrating the distinct correlates of proactive and reactive physical and relational aggression in samples of children (e.g., Crick and Dodge, 1996) and young adults (e.g., Bailey and Ostrov, 2008). However, this study is the first to provide empirical support for the distinction between proactive, reactive, and romantic relational aggression in an adult sample. In particular, the results of the CFA showed that the three-factor model (separate latent factors for proactive, reactive, and romantic relational aggression) fit the data quite well. Moreover, when compared to competing models in which the factors were collapsed in various ways, the three-factor model provided the best fit for the data.

The results also suggest that aggression researchers and clinicians should attend to the context of relationally aggressive behavior among adults. Specifically, consistent with the importance of romantic relationships in late adolescence and adulthood, romantic relational aggression was uniquely associated with anger, hostility, impulsivity, abuse, hostile attribution biases, and feelings of distress regarding relational provocation, even when controlling for peer-directed relational aggression. Although previous studies have assessed romantic relational aggression (e.g., Linder et al., 2002), this is the first study to demonstrate that relational aggression in this context predicts important outcomes above and beyond peer-directed relational aggression. As such, a complete understanding of relational aggression in adults requires inclusion of relational aggression in the context of both peer and romantic relationships.

The second goal was to examine gender differences in relational aggression in adulthood. Consistent with hypotheses, men and women did not differ in their overall use of relational aggression. These findings are consistent with previous research with young adults (Bailey and Ostrov, 2008; Basow et al., 2007; Burton et al., 2007; Loudin et al., 2003) and suggest that as males and females increasingly interact in adolescence and adulthood, males may learn how to effectively employ relationally aggressive strategies from female friends and romantic partners. Interestingly, gender differences in engagement in subtypes of relational aggression were observed. Specifically, females were more likely than males to engage in romantic relational aggression whereas males were more likely than females to engage in peer-directed proactive and reactive relational aggression. Gender differences in specific subtypes of relational aggression may help explain some inconsistent findings regarding gender differences in relational aggression among adults (e.g., Storch et al., 2004). These findings also suggest that as females get older, they may transfer relationally aggressive behaviors learned in the peer context to interactions with romantic partners. Moreover, although men are as likely as women to use relational aggression, they are more likely than women to engage in such behaviors in the peer context. It is possible that males learn and use relational aggression when interacting with female peers. Further research with more diverse adult samples is warranted to replicate these findings and to explore potential reasons for gender differences in subtypes of relational aggression. 
The findings can be interpreted in light of a recent study which provides additional detail regarding the nature of female-to-male aggression (Nelson et al., 2008b). In this study, emerging adults' normative perceptions of aggression were assessed across dyads in which the perpetrator and target varied by gender (male-to-male, female-to-female, male-to-female, female-to-male). Although romantic relational aggression was not expressly considered (participants simply were asked to list what women generally do when they want to be hurtful to men), the findings nonetheless show the prominent place of relational aggression in the actions of females against males. Moreover, much of this aggression is expected to occur in romantic relationships. Emerging adults perceive that females are particularly likely to engage in variants of relational aggression when the target is male. In contrast, male-to-female aggression was predominantly characterized by verbal aggression, according to the perceptions of respondents. The results of the present study with adults ranging in age from 25 to 45 are thus consistent with young adults' perceptions regarding the typical interpersonal contexts of relational aggression.

Finally, our results from the second study indicated that adults with IED exhibited heightened levels of relational aggression when compared to healthy controls and psychiatric controls. These results held even when controlling for general functioning and physical aggression. The findings suggest that relational aggression provides important information regarding clinical symptoms during adulthood. In fact, clinicians may benefit from including assessments of relational aggression when gathering information about participants' aggressive conduct since relational aggression was associated with IED even when controlling for physically aggressive conduct. In other words, assessment of relational aggression may provide clinicians with a more comprehensive picture of patients' aggressive problems than focusing exclusively on physical aggression. We hope that this paper provides a first step in the development of a reliable and valid method for clinicians to assess relational aggression.

Despite the large sample and novel nature of the study, there were several limitations which should be addressed. First, our findings may not generalize to samples that are non-twin (for Study 1) or from other cultural, economic, or ethnic backgrounds (Study 1 and Study 2). For example, it is possible that the unique experiences of being a twin may affect engagement in relational aggression. For instance, evidence suggests that twins experience higher levels of intimacy with their co-twin relative to their closest friends (e.g., Foy et al., 2001), and high levels of intimacy have been related to involvement in relational aggression (Murray-Close et al., 2007). As a result, twins may be at especially high risk for engagement in relational aggression. However, since the focus of this study is on the psychometric properties of the measure of relational aggression and the association between relational aggression and outcome measures (rather than on mean levels of relational aggression), we believe that the findings will generalize to non-twin populations as well. In particular, although twins might exhibit higher levels of relational aggression than their peers, we would expect that the unique correlates of proactive and reactive relational aggression would be similar across samples.

Future research should also focus on the development of appropriate measures of relational aggression among groups differing in socioeconomic status and ethnicity (see Crick et al., 2007) for a discussion of age, gender, and cultural considerations in the study of relational aggression). Although some research has documented the presence of physical and relational forms of aggression among children in a variety of cultures (e.g., French et al., 2002; Hart et al., 1998; Russell et al., 2003; Tomada and Schneider, 1997), it is possible that the correlates of involvement in relational aggression may differ across cultural contexts; for example, relational aggression may be associated with greater levels of maladjustment in cultures such as Japan that place a relative emphasis on harmony in interpersonal relationships (see Crick et al., 2007). In addition, it is important that future researchers develop and validate measures of relational aggression using culturally-sensitive approaches (Crick et al., 2007).

An additional limitation is that only self-report methods were used in the present study and some of the associations may be due to shared-method variance. All methods that were used here have demonstrated reliability and validity and have been widely used in the psychology and psychiatry literatures. However, future research should replicate the findings using additional methods of assessment. The present analyses were all concurrent and longitudinal designs are needed to demonstrate the development of subtypes of relational aggression across the lifespan. In addition, the subscale assessing romantic relational aggression included items assessing proactive and reactive functions of aggression. Future research would benefit from the development of a measure of separate proactive and reactive subtypes of romantic relational aggression so that the unique correlates of each can be assessed. Finally, future research would benefit from further examination of the association between clinical problems and relational aggression among adults. For example, research assessing the association between relational aggression and adjustment, controlling for clinical disorders such as IED, would be very important. In addition, studies exploring the role of relational aggression in the context of clinical disorders such as bipolar disorder are sorely needed.

In conclusion, this study demonstrated the utility of a recently introduced measure of proactive, reactive, and romantic relational aggression in a large adult sample. Overall, this instrument demonstrated good reliability and validity. The present findings suggest that we should not eliminate the proactive and reactive function types from our investigations of aggressive behavior problems in adulthood. Moreover, researchers and clinicians interested in relational aggression in adulthood should examine such behaviors in the context of both peer and romantic relationships. Future research should examine the development of gender differences in subtypes of relational aggression in adult samples. Finally, research should further explore the association between clinical problems and relational aggression. Given the ease of use of this self-report measure, we hope that future researchers will include assessments of these subtypes of relational aggression to better capture a wider array of adult behavior problems.

\section{Role of funding source}

This study was funded in part by NIMH Grants RO1MH63262 and R01MH80109 (Dr. Coccaro). NIMH had no further role in the preparation of this manuscript for publication.

\section{Conflict of interest statement}

None declared.

\section{Acknowledgements}

Special thanks to study participants. This study was funded in part by NIMH Grants R01MH63262 and RO1MH80109(Dr. Coccaro).

\section{References}

American Psychiatric Association. Diagnostic and statistical manual of mental disorders: DSM-IV, 4th ed. Washington, DC: American Psychiatric Association; 1994.

Bagner DM, Storch EA, Preston AS. Romantic relational aggression: what about gender? Journal of Family Violence 2007;22:19-24. 
Bailey CA, Ostrov JM. Differentiating forms and functions of aggression in emerging adults: associations with hostile attribution biases and normative beliefs. Journal of Youth and Adolescence 2008;37:713-22.

Basow SA, Cahill KF, Phelan JE, Longshore K, McGillicuddy-DeLisi A. Perceptions of relational and physical aggression among college students: effects of gender of perpetrator, target, and perceiver. Social Behavior and Personality 2007;31:85-95.

Bernstein DP, Fink L. Childhood Trauma Questionnaire: a retrospective self-report manual. San Antonio, TX: Psychological Corporation; 1998.

Bernstein DP, Fink L, Handelsman L, Foote J, Lovejoy M, Wenzel K, et al. Initial reliability and validity of a new retrospective measure of child abuse and neglect. American Journal of Psychiatry 1994;151:1132-6.

Björkqvist K. Sex differences in physical, verbal, and indirect aggression: a review of recent research. Sex Roles 1994;30:177-87.

Burton LA, Hafetz J, Henninger D. Gender differences in relational and physical aggression. Social Behavior and Personality 2007;35:41-50.

Buss AH, Perry M. The aggression questionnaire. Journal of Personality and Social Psychology 1992;63:452-9.

Card NA, Little TD. Proactive and reactive aggression in childhood and adolescence. A meta-analysis of differential relations with psychosocial adjustment. International Journal of Behavioral Development 2006;30:466-80.

Coccaro EF, Jacobson KC. PennTwins: a population based cohort for twin studies. Twin Research 2006;9:998-1005.

Coccaro EF, Noblett KL, McCloskey MS. Attributional and emotional responses to socially ambiguous cues: validation of a new assessment of social/emotional information processing in healthy adults and impulsive aggressive patients. Journal of Psychiatric Research 2009;43:915-25.

Coccaro EF, Schmidt CS, Samuels J, Nestadt G. Lifetime and one-month prevalence rates of Intermittent Explosive Disorder in a community sample. Journal of Clinical Psychiatry 2004;65:820-4.

Cohen J, Cohen P. Applied multiple regression/correlation analysis for the behavioral sciences. 2nd ed. Hillsdale, NJ: Lawrence Erlbaum Associates; 1983.

Crick NR. Relational aggression: the role of intent attributions, provocation type, and feelings of distress. Development and Psychopathology 1995;7:313-22.

Crick NR, Dodge KA. A review and reformulation of social information-processing mechanisms in children's social adjustment. Psychological Bulletin 1994:115:74-101.

Crick NR, Dodge KA. Social information-processing mechanisms in reactive and proactive aggression. Child Development 1996;67:993-1002.

Crick NR, Grotpeter JK. Relational aggression, gender, and social-psychological adjustment. Child Development 1995;66:710-22.

Crick NR, Grotpeter JK, Bigbee MA. Relationally and physically children's intent attributions and feelings of distress for relational and instrumental peer conflicts. Child Development 2002;73:1134-42.

Crick NR, Murray-Close D, Woods K. Borderline personality features in childhood: a short-term longitudinal study. Development and Psychopathology 2005;17: 1051-70.

Crick NR, Ostrov JM, Kawabata Y. Relational aggression and gender: an overview. In: Flannery DJ, Vazsonyi AT, Waldman ID, editors. The Cambridge handbook of violent behavior and aggression. New York, NY: Cambridge University Press; 2007. p. 245-59.

Crick NR, Werner NE, Casas JF, O'Brien KM, Nelson DA, Grotpeter JK, et al. Childhood aggression and gender: a new look at an old problem. In: Bernstein D, editor. Nebraska symposium on motivation. Lincoln: University of Nebraska Press; 1999.

Day DM, Bream LA, Pal A. Proactive and reactive aggression: an analysis of subtypes based on teacher perceptions. Journal of Clinical Child Psychology 1992;21: 210-7.

Dillman DA. Mail and Internet surveys: the tailored design method. 2nd ed. New York, NY: John Wiley \& Sons; 2000.

Dodge KA. The structure and function of reactive and proactive aggression. In: Pepler KH, Rubin DJ, editors. The development and treatment of childhood aggression. Hillsdale, NJ: Lawrence Erlbaum Associates; 1991.

Dodge KA, Coie JD. Social information-processing factors in reactive and proactive aggression in children's playgroups. Journal of Personality and Social Psychology 1987;53:1146-58.

Dodge KA, Coie JD, Lynam D. In: Damon W, editor. Handbook of Child Psychology. 6th ed. Eisenberg N, editors. Social, emotional, and personality development 2006;vol. 3. New York: Wiley; 2006. p. 719-88.

Dodge KA, Lochman JE, Harnish JD, Bates JE, Pettit GS. Reactive and proactive aggression in school children and psychiatrically impaired chronically assaultive youth. Journal of Personality and Social Psychology 1997;53:1146-58.

First MB, Gibbon M, Williams JBW. Structured clinical interview for DSM-IV axis disorders (SCID). New York: Psychiatric Institute, Biometrics Research; 1997.

Fite PJ, Colder CR, Pelham WE. A factor analytic approach to distinguish pure and cooccurring dimensions of proactive and reactive aggression. Journal of Clinica Child and Adolescent Psychology 2006;35:578-82.

Foy AK, Vernon PA, Jang K. Examining the dimensions of intimacy in twin and peer relationships. Twin Research 2001;4:443-52.

French DC, Jansen EA, Pidada S. United States and Indonesian children's and adolescents' reports of relational aggression by disliked peers. Child Development 2002;73:1143-50.

Furman W, Buhrmester D. Children's perceptions of the personal relationships in their social networks. Developmental Psychology 1985;21:1016-24.

Goldstein SE, Chesir-Teran D, McFaul A. Profiles and correlates of relational aggression in young adults' romantic relationships. Journal of Youth and Adolescence 2008;37:251-65.
Grotpeter JK, Crick NR. Relational aggression, overt aggression, and friendship. Child Development 1996:67:2328-38.

Hart CH, Nelson DA, Robinson CC, Olsen SF, McNeilly-Choque MK. Overt and relational aggression in Russian nursery-school-age children: parenting style and marital linkages. Developmental Psychology 1998;34:687-97.

Hubbard JA, Dodge KA, Cillessen AHN, Coie JD, Schwartz D. The dyadic nature of social information processing in boys' reactive and proactive aggression. Journal of Personality and Social Psychology 2001;80:268-80.

Hubbard JA, Parker EH, Ramsden SR, Flanagan KD, Relyea N, Dearing KF, et al. The relations among observational, physiological, and self-report measures of children's anger. Social Development 2004;13:14-39.

Hubbard JA, Smithmyer CM, Ramsden SR, Parker EH, Flanagan KD, Dearing KF, et al. Observational, physiological, and self-report measures of children's anger: relations to reactive versus proactive aggression. Child Development 2002;73:1101-18.

Keenan K, Coyne C, Lahey BB. Should relational aggression be included in DSM-V? Journal of the American Academy of Child \& Adolescent Psychiatry 2008;47:86-93.

Klein DN, Ouimette PC, Kelly HS, Ferro T, Riso LP. Test-retest reliability of team consensus best-estimate diagnoses of axis I and II disorders in a family study. American Journal of Psychiatry 1994;151:1043-7.

Kosten TA, Rounsaville BJ. Sensitivity of psychiatric diagnosis based on the best estimate procedure. American Journal of Psychiatry 1992;149:1225-7.

Leckman JF, Sholomskas D, Thompson WD, Belanger A, Weissman MM. Best estimate of lifetime psychiatric diagnosis: a methodological study. Archives of General Psychiatry 1982;39:879-83.

Lento-Zwolinski J. College students' self-report of psychosocial factors in reactive forms of relational and physical aggression. Journal of Social and Personal Relationships 2007;24:407-21.

Linder JR, Crick NR, Collins WA. Relational aggression and victimization in young adults' romantic relationships: associations with perceptions of parent, peer, and romantic relationship quality. Social Development 2002;11:69-86.

Little TD, Jones SM, Henrich CC, Hawley PH. Disentangling the "whys" from the "whats" of aggressive behavior. International Journal of Behavioral Development 2003;27:122-33.

Loudin JL, Loukas A, Robinson S. Relational aggression in college students: examining the roles of social anxiety and empathy. Aggressive Behavior 2003;29:430-9

Maccoby EE. Gender and relationships: a developmental account. American Psychologist 1990;45:513-20.

Miller JD, Lynam DR. Psychopathy and the five-factor model of personality: a replication and extension. Journal of Personality Assessment 2003;81:168-78.

Morales JR, Crick NR. Self-report measure of aggression and victimization. Unpublished measure. Twin Cities Campus: University of Minnesota; 1998

Murray-Close D, Ostrov JM, Crick NR. A short-term longitudinal study of growth of relational aggression during middle childhood: associations with gender, friendship intimacy, and internalizing problems. Development \& Psychopathology 2007;19:187-203.

Nelson DA, Mitchell C, Yang C. Intent attributions and aggression: a study of children and their parents. Journal of Abnormal Child Psychology 2008a;36:793-806.

Nelson DA, Springer MM, Nelson LJ, Bean NH. Normative beliefs regarding aggression in emerging adulthood. Social Development 2008b;17:638-60.

Ohan JL, Johnston C. Gender appropriateness of symptom criteria for attentiondeficit/hyperactivity disorder, oppositional-defiant disorder, and conduct disorder. Child Psychiatry \& Human Development 2005;35:359-81.

Orobio de Castro B, Merk W, Koops W, Veerman JW, Bosch JD. Emotions in social information processing and their relations with reactive and proactive aggression in referred aggressive boys. Journal of Clinical Child and Adolescent Psychology 2005;34:105-16.

Ostrov JM, Houston RJ. The utility of forms and functions of aggression in emerging adulthood: association with personality disorder symptomatology. Journal of Youth and Adolescence 2008;37:1147-58.

Patton JH, Stanford MS, Barratt ES. Factor structure of the Barratt Impulsiveness Scale. Journal of Clinical Psychology 1995;51:768-74.

Pfohl B, Blum N, Zimmerman M. Structured interview for DSM-IV personality: SIDPIV. Washington, DC: American Psychiatric Press; 1997.

Poulin F, Boivin M. Reactive and proactive aggression: evidence of a two-factor model. Psychological Assessment 2000;12:115-22.

Price JM, Dodge KA. Reactive and proactive aggression in childhood: relations to peer status and social context dimensions. Journal of Abnormal Child Psychology 1989;17:455-71.

Pulkkinen L. Proactive and reactive aggression in early adolescence as precursors to anti- and prosocial behaviors in young adults. Aggressive Behavior 1996;22:241-57.

Raine A, Dodge K, Loeber R, Gatzke-Kopp L, Lynam D, Reynolds C, et al. The reactiveproactive aggression questionnaire: differential correlates of reactive and proactive aggression in adolescent boys. Aggressive Behavior 2006;32:159-71.

Russell A, Hart CH, Robinson C, Olsen SF. Children's sociable and aggressive behavior with peers: a comparison of the US and Australia, and contributions of temperament and parenting styles. International Journal of Behavioral Development 2003;27:74-86.

Salmivalli C, Nieminen E. Proactive and reactive aggression among school bullies, victims, and bully-victims. Aggressive Behavior 2002;28:30-44.

Schad MM, Szwedo DE, Antonishak J, Hare A, Allen JP. The broader context of relational aggression in adolescent romantic relationships: predictions from 
peer pressure and links to psychosocial functioning. Journal of Youth and Adolescence 2008;37:346-58.

Schwartz D, Dodge KA, Coie JD, Hubbard JA, Cillessen AHN, Lemerise EA, et al. Social-cognitive and behavioral correlates of aggression and victimization in boys' play groups. Journal of Abnormal Child Psychology 1998;26:431-40.

Spielberger CD. State-trait anger expression inventory manual. Odessa, FL: Psychological Assessment Resources; 1996.

Standford MS, Houston RJ, Mathias CW, Villemarette-Pittman NR, Helfritz LE, Conklin SM. Characterizing aggressive behavior. Assessment 2003;10:183-90.

Storch EA, Bagner DM, Geffken GR, Baumeister AL. Association between overt and relational aggression and psychosocial adjustment in undergraduate college students. Violence \& Victims 2004;19:689-700.

Tomada G, Schneider BH. Relational aggression, gender, and peer acceptance. Invariance across culture, stability over time, and concordance among informants. Developmental Psychology 1997;33:601-9.

Vitaro F, Gendreau PL, Tremblay RE, Oligny P. Reactive and proactive aggression differentially predict later conduct problems. Journal of Child Psychology and Psychiatry 1998;39:377-85.
Waschbusch DA, Pehlam Jr WE, Jennings JR, Greiner AR, Tarter RE, Moss HB Reactive aggression in boys with disruptive behavior disorders: behavior, physiology, and affect. Journal of Abnormal Child Psychology 2002;30:641-56.

Waschbusch DA, Willoughby MT, Pelham WE. Criterion validity and the utility of reactive and proactive aggression: comparisons to attention deficit hyperactivity disorder, oppositional defiant disorder, conduct disorder, and other measures of functioning. Journal of Clinical Child Psychology 1998;27:396-405.

Werner NE, Crick NR. Relational aggression and social-psychological adjustment in a college sample. Journal of Abnormal Psychology 1999;108:615-23.

Yang C, Hart CH, Nelson DA, Porter CL, Olsen SF, Robinson CC, et al. Fathering in a Beijing Chinese sample: associations with boys' and girls' negative emotionality and aggression. In: Day RD, Lamb ME, editors. Conceptualizing and measuring father involvement. Mahwah, NJ: Lawrence Erlbaum Associates; 2004. p. 185-215.

Zalecki CA, Hinshaw SP. Overt and relational aggression in girls with attention deficit hyperactivity disorder. Journal of Clinical Child and Adolescent Psychology 2004;33:125-37. 